\title{
Moderate Inflation and the Deflation-Depression Link
}

\author{
Jess Benhabib \\ New York University \\ Mark M. Spiegel \\ Federal Reserve Bank of San Francisco
}

October 2006

Working Paper 2006-32

http://www.frbsf.org/publications/economics/papers/2006/wp06-32bk.pdf

The views in this paper are solely the responsibility of the authors and should not be interpreted as reflecting the views of the Federal Reserve Bank of San Francisco or the Board of Governors of the Federal Reserve System. This paper was produced under the auspices for the Center for Pacific Basin Studies within the Economic Research Department of the Federal Reserve Bank of San Francisco. 


\title{
Moderate Inflation and the Deflation-Depression Link
}

\author{
Jess Benhabib \\ New York University \\ And \\ Mark M. Spiegel* \\ Federal Reserve Bank of San Francisco
}

October 11, 2006

\begin{abstract}
In a recent paper, Atkeson and Kehoe (2004) demonstrated the lack of a robust empirical relationship between inflation and growth for a cross-section of countries with $19^{\text {th }}$ and $20^{\text {th }}$ century data, concluding that the historical evidence only provides weak support for the contention that deflation episodes are harmful to economic growth. In this paper, we revisit this relationship by allowing for inflation and growth to have a nonlinear specification dependent on inflation levels. In particular, we allow for the possibility that high inflation is negatively correlated with growth, while a positive relationship exists over the range of negative-to-moderate inflation. Our results confirm a positive relationship between inflation and growth at moderate inflation levels, and support the contention that the relationship between inflation and growth is non-linear over the entire sample range.
\end{abstract}

\section{Keywords: Inflation, growth, empirics}

JEL Classification: E5, E52, E58, E6, E65, E42, E3, E31

*Corresponding author. We thank Andy Atkeson, David Backus and Warren Weber for providing us with the data. The views expressed in this paper are our own and do not necessarily reflect those of the Federal Reserve Board of Governors or the Federal Reserve Bank of San Francisco. 


\section{Introduction}

This paper is a note on Atkeson and Kehoe (2004), "Deflation and Depression: Is There an Empirical Link?” Policymakers since the Great Depression have indeed been much concerned that deflation can lead to lower growth rates, if not recessions, and the recent Japanese experience has exacerbated such concerns [see Krugman,(1997)]. Theoretical models offer differing perspectives. Milton Friedman's argument that for economic efficiency the nominal interest rate should be zero and that the price level should fall steadily at the real rate of interest is well known, and has been formally reconfirmed by Chari, Christiano, and Kehoe (1996) and by Cole and Kocherlakota (1998) [See also Benhabib and Bull (1983)]. Others, working with calibrated models embedding sticky prices and market distortions, find the Friedman rule non-optimal [Schmitt-Grohe and Uribe (2004)]. More to the point, Auerbach and Obstfeld (2005) find that the welfare and output costs associated with liquidity traps and deflations can be very significant.

Our purpose is not to resolve the differences or to propose another theoretical model, but to further pursue the empirical approach of Atkeson and Kehoe by introducing an additional perspective. Folklore has it that too much inflation (hyperinflation) is bad for the economybecause it increases "shoe-leather" costs, and that deflation is also bad because prices are sticky, or because of other less-well understood reasons that have something to do with expectations. If so, we should not expect a linear relation between growth and inflation, but an inverted U-shaped one. In this note we want to extend Atkeson and Kehoe by considering such a non-linear relationship. ${ }^{1}$

\footnotetext{
${ }^{1}$ See also Bruno and Easterly (1998) and Ghosh and Phillips (1998).
} 
Following the methodology of Atkeson and Kehoe, we are only attempting to characterize the empirical relationship between inflation and economic growth, and do not claim that there are any causal conclusions one can draw from our results. Our analysis speaks to Atkeson and Kehoe's conclusion based on a linear specification that that data show no obvious relationship, which raises the bar those who claim that deflation and depression are closely linked.

Using a long cross-country panel data set of five-year growth episodes, we first confirm Atkeson and Kehoe's findings of a relatively weak correlation between inflation and growth under a simple linear specification. However, we then demonstrate that when one allows for a non-linear relationship so as to capture an inverted-U shape, both the economic and statistical strength of the relationship increase dramatically in samples limited to moderate-to-negative inflation.

We then divide the sample according to inflation levels, examining the relationship in a simple linear specification for samples with average five-year inflation levels below and above $5 \%, 10 \%$, and $15 \%$. Our results again show that for sub-samples limited to negative and moderate inflation levels, the relationship between inflation and growth is quite strong, with the coefficient estimate for the sub-sample of inflation levels below 5\% being almost four times that of the full sample Atkeson and Kehoe specification. F-tests confirm the instability of the inflation coefficient across these thresholds under a linear specification.

Finally, we examine the robustness of our results to conditioning for the volatility of inflation. It has been argued [e.g. Barro (1976), Judson and Orphanides (1999)] that it is inflation volatility, rather than inflation itself, that is the primary cause of poor 
economic performance during high inflation episodes. Nevertheless, our basic results are robust to conditioning for inflation volatility, in that we continue to observe that growth is positively related to inflation at moderate inflation levels and that the relationship between inflation and output exhibits instability when one crosses from moderate to high inflation levels.

\section{Data}

Our data set is very similar to that in Atkeson and Kehoe [AK (2004)]. ${ }^{2}$ Data on the general price level and output data up to 1980 are obtained from Rolnick and Weber (1997) and Backus and Kehoe (1992) for Argentina (from 1885), Australia (from 1862), Brazil (1861), Canada (1870), Chile (1908), Denmark (1871), France (1820), Germany (1830), Italy (1867), Japan (1885), Netherlands (1900), Norway (1865), Portugal (1833), Spain (1849), Sweden (1861), United Kingdom (1870), and the United States (1820). This data runs from early periods to 1992 through 1995 depending on the country. Remaining years are filled in using data from the IMF's International Financial Statistics.

As in AK, we group the data into five-year episodes that start and end in years 9 or 4 , so that the entire depression is contained in a single five year sub-sample. We also follow AK by restricting our attention to moderate inflation or deflation, by restricting our sample to five year periods that average less than $20 \%$ inflation or deflation.

However, as a control, we also examine a sample that includes all five year periods that

\footnotetext{
${ }^{2}$ We have five extra years of data for Italy, 1862-1867, and one extra year for Argentina, Australia and Denmark, 1884, 1861, and 1870 respectively.
} 
average less than $40 \%$ inflation or deflation, the sample selection chosen by Bruno and Easterly (1998).

Summary statistics are shown in Table 1 for samples excluding five year periods with average inflation or deflation exceeding 40 and 20 percent respectively. Over the full sample, our data exhibits a positive correlation between average growth and average inflation equal to 0.14 for both the less than $40 \%$ and less than $20 \%$ samples. However, the pre-and post World War II sub-samples demonstrate that the results are likely to be sensitive to the sample truncation rule chosen. For the pre-World War II sample, the less than $40 \%$ truncation reveals a relatively small correlation between inflation and growth equal to 0.03 while the less than $20 \%$ sample exhibits a larger 0.17 correlation coefficient. In contrast, the post-World War II sample shows a 0.15 correlation between inflation and growth for the $40 \%$ sample, while the less than $20 \%$ sample demonstrates a smaller correlation equal to 0.08 .

As discussed above, we examine the robustness of our results to conditioning for the volatility of inflation, $\sigma_{\pi}^{2}$, which we measure as

$$
\sigma_{\pi t}^{2} \equiv \frac{1}{n} \sum_{i=1}^{n}\left(\pi_{i t}-\bar{\pi}_{t}\right)^{2}
$$

where $n=5$ is the length of individual years in each observation period and $\bar{\pi}_{t}$ is the mean level of inflation in period $t$. Table 1 demonstrates that there is a strong correlation between the level of inflation and the volatility of inflation, as would be expected. We also tend to find a negative correlation between economic growth and inflation volatility, with the exception of the post-World War II sub-sample. 


\section{Non-linear Specification}

We first estimate the relationship between inflation and growth under the following simple specification

$$
\Delta y_{i t}=\alpha+\beta_{1} \pi_{i t}+\beta_{2}\left(\pi_{i t}\right)^{2}+\varepsilon_{i t}
$$

where $\Delta y_{i t}$ represents average annual growth for country $i$ during five-year period $t, \pi_{i t}$ represents average annual inflation for country $i$ during five-year period $t$, and $\varepsilon_{i t}$ represents an i.i.d. normal disturbance term. We impose the restriction that the coefficient on the nonlinear term is zero for our linear benchmark and then run the specification again with the coefficient unrestricted. We estimate using ordinary least squares with White's correction for heteroskedasticity.

Our results are shown in Table 2 for the less than $20 \%$ and less than $40 \%$ samples respectively. We run the specification for the full sample and for three historic subsamples. Our first sub-sample excludes the depression five year period, 1929-1934, and the WWII period, 1939-1949. ${ }^{3}$ Our other two samples include dates before and after this WWII period.

Looking first at the linear specifications for the sample with inflation rates below $20 \%$, it can be seen that inflation enters with a positive point estimate for all of these specifications for both samples, and significantly at a five percent confidence level for the full sample and the sample excluding the Great Depression and WWII, and at a tenpercent confidence level for the Before WWII sub-sample. However, inflation is

\footnotetext{
${ }^{3}$ This specification of the Second World War period follows Atkeson and Kehoe (2004).
} 
insignificant for the After WWII sample. Since this sample largely matches that in AK, it is unsurprising that we obtain a similar point estimate of 0.083 for the full sample. When we include inflation episodes up to an average of $40 \%$, the correlation under a linear specification is uniformly weaker, and only statistically significant for the full sample. Overall, our linear results confirm the AK finding of a modest, if any, correlation between inflation and growth.

We next allow the nonlinear term to be non-zero. As expected, the nonlinear term enters negatively in all specifications, although not always at statistically significant levels. It is significant at a 5\% confidence level for our full sample. However, the more interesting result is that allowing for the non-linear term markedly increases the economic and statistical significance of the coefficient on the level of inflation. In the case of the full sample below $20 \%$ inflation, the coefficient on the inflation level more than doubles, to 0.193 , and is now significant at a $1 \%$ confidence level. We see similar increases when we include the larger under $40 \%$ inflation sample, or for the sub-sample excluding the Great Depression and WWII or the Before WWII sub-sample. The exception is the post-WWII sub-sample, which doesn'texhibit a significant relationship between inflation and growth in either the linear or non-linear specifications.

With the exception of that sub-sample, our results strongly indicate that allowing for a non-linear inflation term significantly increases the measured linear relationship between inflation and growth. The data driving this result can be seen in Figure 1, which plots the below 20 samples and the fitted nonlinear specifications. Again, except for the post-WWII sub-sample, we find a pronounced nonlinear relationship between inflation and growth. Concentrating on the full sample, it can be seen that this nonlinearity is 
driven by the fact that episodes of very poor economic performance tend to be associated with high or low inflation levels, while episodes of exceptionally strong economic performance tend to be clustered around modest inflation levels. ${ }^{4}$

\section{Sample split into high and moderate inflation levels}

The results above provide some indication that the relation between inflation and economic performance is nonlinear, although the sample may be too noisy to closely fit a nonlinear specification. In this section, we instead split our samples in two, above and below some threshold that may be associated with the level at which inflation begins to become problematic. Because the value at which this may occur is uncertain, we examine a variety of potential inflation thresholds, including $5 \%, 10 \%$, and $15 \%$ sample splits. We then conduct an F-test to determine whether or not the data suggest that the coefficient estimate on the level of inflation is stable above and below this threshold.

For each sub-sample, we first estimate the simple linear specification

$$
\Delta y_{i t}=\alpha+\beta_{1} \pi_{i t}+\varepsilon_{i t}
$$

above and below the 5\% threshold for the below $20 \%$ sample. $^{5}$

Our results are shown in Table 3. For the full sample, it can be seen that there is a robust positive correlation between inflation and annual growth below all three of our

\footnotetext{
${ }^{4}$ There are outliers. One notable one in our sample is that of the Netherlands from 1944-1949, which experienced a remarkable $21.28 \%$ average economic growth along with very high $1336 \%$ average inflation levels. Of course, the rapid economic growth can be associated with recovery from the war, which is why we also examine the results excluding the exceptional war and great depression episodes.

${ }^{5}$ We use the $20 \%$ cutoff because it corresponds to AK. Using the larger $40 \%$ cutoff would obviously only affect the above-threshold sample, while the results below the specified threshold would be identical.
} 
posited thresholds. As expected, we obtain the strongest results for the lowest threshold, i.e. for inflation below 5\%. For that sub-sample, we obtain a coefficient estimate on inflation equal to 0.32 , close to four times the value of the estimate we obtained for the full sample. This point estimate indicates that a $1 \%$ increase in the inflation rate would correspond to a $0.32 \%$ increase in the annual growth rate over a five year period. The estimate is statistically significant at a $1 \%$ confidence level. Above the $5 \%$ threshold, we obtain a very insignificant negative point estimate for relationship between inflation and growth. Our F-test result confirms that the coefficient on inflation is unstable across the $5 \%$ threshold.

Moving to higher threshold levels, our qualitative results remain the same. We obtain positive and statistically significant point estimate for the relationship between inflation and growth below the $10 \%$ and $15 \%$ thresholds at $1 \%$ and $5 \%$ confidence levels respectively, while the coefficients above these thresholds are negative and insignificant. Interestingly, the point estimate on the coefficient diminishes as the size of the threshold increases. Our point estimate for the sample below $10 \%$ inflation falls to 0.15 , roughly half the size of the below-5\% threshold, and falls again to 0.10 for the below- $15 \%$ threshold. This suggests that the positive relationship between inflation and growth diminishes above modest inflation levels. Our F-test for a structural break above and below the $15 \%$ threshold is insignificant.

The results for the sub-sample excluding the Great Depression and WWII episodes are similar. We obtain a positive and statistically significant coefficient on inflation below all of our posited thresholds, and our point estimates again decrease with the size of the threshold. Above all three thresholds, we obtain negative, but insignificant 
coefficient estimates. F-tests confirm the presence of a structural break at statistically significant levels for the $5 \%$ and $10 \%$ thresholds, but not for the $15 \%$ threshold.

We also obtain similar results for the Before-WWII sub-sample. The coefficient estimate on the inflation rate is positive and significant for all three thresholds, and decreases in the size of the threshold. Above all three thresholds, our point estimates are modestly negative and insignificant. F-tests confirm the presence of a structural break at a $1 \%$ confidence level for the $5 \%$ and $10 \%$ thresholds, and at a $10 \%$ confidence level for the $15 \%$ threshold.

The great exception, again, is the post-WWII sample, which is insignificant above and below all three posited thresholds. Unsurprisingly, the data also fail to confirm the presence of a structural break across all three thresholds. Still, even for this sub-sample we obtain a relatively large point estimate on the inflation coefficient of 0.16 for the sample including inflation levels below 5\%.

Overall, dividing the sample above and below some threshold value gave a much stronger indication that there was a positive relationship between inflation and growth for modest inflation levels. A notable exception is the post-World War II period, which failed to demonstrate a structural break at statistically significant levels for either sample.

\section{Inflation volatility}

In this section, we examine the robustness of our results to the inclusion of a measure of inflation volatility, measured as the variance of inflation over the five year 
period. We examine the same specifications as those above with inflation volatility measure added.

Our results are shown in Table 4. Table 4.1 repeats the non-linear specification from Table 2 for the full sample and the sub-sample with the Great Depression and WWII periods excluded. It can be seen that our point estimates for the inflation coefficient and the nonlinear term are basically unchanged. The inclusion of a nonlinear term results in a large increase in the coefficient on inflation in levels, to 0.19 for the full sample. Inflation volatility enters negatively, but is insignificant except for the linear specification with the Great Depression and WWII removed, and then only at a 10\% confidence level.

We add our measure of inflation volatility to the linear specifications with structural breaks in Table 4.2. Our coefficient estimates for the below-threashold subsamples are almost identical to those in Table 3. We again obtain a coefficient estimate of 0.32 for the below- $5 \%$ sub-sample, and our point estimate diminishes as the structural break threshold increases. As before, our F-tests identify a statistically-significant structural break at the 5\% and 10\% threshold levels, but not at the $15 \%$ threshold level. The results for the below-threshold sub-sample for the sample excluding the Great Depression and WWII are also similar.

The major innovation from including inflation volatility arises in the abovethreshold sub-samples. Inflation in levels is still very insignificant, but inflation volatility enters negatively at a $1 \%$ confidence level for all of our posited thresholds. This result suggests that the harmful effects of high inflation episodes is associated with the 
volatility of inflation rather than the level of inflation, which is in keeping with the previous literature.

\section{Conclusion}

This paper reexamines the long-term evidence on inflation and economic performance by allowing for inflation and economic performance to follow a non-linear relationship. We find that for low and negative inflation levels, the correlation between inflation and economic performance is quite strong. Below a 5\% threshold, our coefficient estimates indicate that a $1 \%$ increase in average inflation levels is associated with a $0.32 \%$ increase in average annual growth. These results are robust to the inclusion of a measure of inflation volatility. Interestingly, we also found that in samples of high inflation episodes it was inflation volatility, rather than inflation itself, that had a measurable adverse impact on economic growth.

We should reiterate Atkeson and Kehoe's acknowledgement that there is no causality claim here, rather as in their case, we are just observing the correlations between these two variables. However, our results contrast sharply with those of Atkeson and Kehoe for low and negative inflation levels, over which the raw data does appear to indicate a strong positive link between inflation and economic performance. At a minimum, the truncated results seem to provide support for effort by monetary authorities to avoid deflationary episodes.

The one exception to our general results is the After-WWII sub-sample, over which we fail to find a statistically significant coefficient between inflation and economic 
performance, even with the sample of episodes below $5 \%$ average inflation. This sample includes the Japanese experience in the 1990s, which exhibited poor growth with deflation. This might lead some to conclude that while a positive relationship existed historically, it has broken down in more modern eras. However, it should be pointed out that our point estimate for the relationship between inflation and growth is quite comparable to the two full sample values, suggesting that there was not a discernable dropoff in the relationship after the war. Instead, it appears that the relationship has grown more noisy, resulting in larger measured standard errors and precluding statistical inference at standard confidence levels. 


\section{References}

Auerbach, Alan J \& Obstfeld, Maurice. (2005). "The Case for Open-Market Purchases in a Liquidity Trap,” American Economic Review, 95, 110-137.

Atkeson, Andrew and Kehoe, Patrick J. (2004). "Deflation and Depression: Is There an Empirical Link?,” American Economic Review, Papers and Proceedings, 94, 99-103.

Backus, David K. and Kehoe, Patrick J. (1992). "Paths of Development for Early- and Late-Bloomers in a Dynamic Heckscher-Ohlin World,” American Economic Review, 82, 864-888.

Barro, Robert J. (1976). "Rational Expectations and the Role of Monetary Policy," Journal of Monetary Economics, 2(1), 1-32.

Benhabib, Jess and Bull, Clive. (1983). “The Optimal Quantity of Money; A Formal Treatment,” International Economic Review, 24, 101-111.

Bruno, Michael and Easterly, William. (1998). "Inflation Crises and Long-Run Growth,” Journal of Monetary Economics, 41(1), 3-26.

Chari, V. V.; Christiano, Lawrence J. and Kehoe, Patrick J. (1996). “Optimality of the

Friedman Rule in Economies with Distorting Taxes.” Journal of Monetary Economics, 37(2), 203-223.

Cole, Harold L. and Kocherlakota, Narayana. (1998). “Zero Nominal Interest Rates: Why

They're Good and How to Get Them,” Federal Reserve Bank of Minneapolis Quarterly Review, Spring, 22(2), 2-10.

Ghosh, Atish, and Phillips, Steven. (1998). "Warning: Inflation may be Harmful to your Growth,” IMF Staff Papers, 45(4), 672-710.

Judson, Ruth and Orphanides, Athanasios. (1999). "Inflation, Volatility and Growth,” International Finance, 2(1), 117-138.

Krugman, Paul, (1998). “It’s Baaack: Japan’s Slump and the Return of the Liquidity Trap,” Brookings Papers on Economic Activity, 1998(2), 137-187.

Rolnick, Arthur J. and Weber, Warren E. (1997). "Money, Inflation, and Output under Fiat and Commodity Standards,” Journal of Political Economy, 105(6), 1-50.

Schmitt-Grohe Stephanie and Uribe, Martin, (2004). "Optimal Fiscal and Monetary Policy under Sticky Prices,”Journal of Economic Theory, February, 114, 198-230. 
Table 1: Summary Statistics

Inflation less than $20 \%$

\begin{tabular}{lccccccc} 
Period & $\begin{array}{c}\text { Average } \\
\text { Inflation }(\pi)\end{array}$ & $\begin{array}{c}\text { Average } \\
\text { Growth }(\dot{y})\end{array}$ & $\begin{array}{c}\text { Inflation } \\
\text { Volatility }\left(\sigma_{\pi}^{2}\right)\end{array}$ & $\rho(\pi, \dot{y})$ & $\rho\left(\pi, \sigma_{\pi}^{2}\right)$ & $\rho\left(\dot{y}, \sigma_{\pi}^{2}\right)$ & \# obs \\
\hline Full Sample & 3.30 & 3.04 & 30.67 & 0.14 & 0.19 & -0.05 & 391 \\
Excluding GD and WWII & 3.22 & 3.19 & 29.84 & 0.13 & 0.17 & -0.08 & 351 \\
Before WWII (Pre-1939) & 0.83 & 2.47 & 44.51 & 0.17 & 0.28 & -0.05 & 193 \\
After WWII (Post-1948) & 5.70 & 3.64 & 15.42 & 0.08 & 0.43 & 0.18 & 171 \\
Great Depression & -3.68 & -0.18 & 25.35 & 0.40 & -0.38 & -0.32 & 16 \\
\end{tabular}

Inflation less than $40 \%$

\begin{tabular}{|c|c|c|c|c|c|c|c|}
\hline Period & $\begin{array}{c}\text { Average } \\
\text { Inflation }(\pi)\end{array}$ & $\begin{array}{c}\text { Average } \\
\text { Growth }(\dot{y})\end{array}$ & $\begin{array}{c}\text { Inflation } \\
\text { Volatility }\left(\sigma_{\pi}^{2}\right) \\
\end{array}$ & $\rho(\pi, \dot{y})$ & $\rho\left(\pi, \sigma_{\pi}^{2}\right)$ & $\rho\left(\dot{y}, \sigma_{\pi}^{2}\right)$ & \# obs \\
\hline Full Sample & 4.42 & 3.07 & 44.42 & 0.14 & 0.49 & 0.02 & 411 \\
\hline Excluding GD and WWII & 4.38 & 3.18 & 41.13 & 0.08 & 0.47 & -0.11 & 370 \\
\hline Before WWII (Pre-1939) & 1.40 & 2.42 & 50.99 & 0.03 & 0.47 & -0.12 & 198 \\
\hline After WWII (Post-1948) & 7.44 & 3.72 & 38.88 & 0.15 & 0.63 & 0.17 & 186 \\
\hline
\end{tabular}

Note: Average levels of and correlations between inflation, growth and volatility. Definition of volatility is in the text. Statistics for Great Depression are the same for $20 \%$ and $40 \%$ samples 


\section{Table 2: Inflation and Growth}

Sample: $\quad$ Inflation less than 20\% Inflation less than $40 \%$

Dependent Variable:

Average Income Growth

Linear Non-Linear Linear Non-Linear

Specification Specification Specification Specification

Full Sample

\begin{tabular}{lcccc}
$\pi$ & $0.083^{* *}$ & $0.193^{* * *}$ & $0.056^{* *}$ & $0.110^{* *}$ \\
$\pi^{2}$ & $(0.036)$ & $(0.059)$ & $(0.028)$ & $(0.050)$ \\
& & $-0.010^{* *}$ & & -0.002 \\
\multirow{2}{*}{ s.tions } & 391 & $(0.004)$ & & $(0.002)$ \\
& & 391 & 411 & 411
\end{tabular}

Excluding GD and WWII

$\begin{array}{lcccc}\pi & 0.068 * * & 0.123 * * & 0.027 & 0.091^{* *} \\ \pi^{2} & (0.031) & (0.058) & (0.025) & (0.043) \\ & & -0.005 & & -0.003 * * \\ \text { servations } & 351 & (0.004) & & (0.002) \\ & & 351 & 370 & 370\end{array}$

Before WWII

$\begin{array}{lcccc}\pi & 0.104^{*} & 0.170^{* *} & 0.015 & 0.177^{* *} \\ \pi^{2} & (0.060) & (0.076) & (0.048) & (0.073) \\ & & -0.010 & & -0.011^{* * *} \\ \text { servations } & & (0.008) & & (0.003) \\ & 193 & 193 & 198 & 198\end{array}$

$\begin{array}{ccccc}\text { After WWII } & & & & \\ \pi & 0.026 & 0.051 & 0.021 & 0.040 \\ & (0.039) & (0.114) & (0.031) & (0.068) \\ \pi^{2} & & -0.002 & & -0.001 \\ & & (0.007) & & (0.002) \\ \text { \# Observations } & 171 & 171 & 186 & 186\end{array}$

Note: Estimation by OLS with White's heteroskedasticity correction. *, **, and ***, indicate statistical significance at 10,5 , and 1 percent levels respectively. 


\section{Table 3: Samples Split by Inflation}

Dependent Variable:

Average Income Growth

$\pi \leq 5 \% \quad \pi>5 \% \quad \pi \leq 10 \% \quad \pi>10 \% \quad \pi \leq 15 \% \quad \pi>15 \%$

\section{Full Sample}

$\pi$

$\begin{array}{cccccc}0.319 * * * & -0.001 & 0.153 * * * & -0.001 & 0.103 * * & -0.001 \\ (0.070) & (0.002) & (0.050) & (0.002) & (0.049) & (0.002)\end{array}$

F-value

$10.36 * * *$

$4.78 * * *$

2.19

\# Observations

$284 \quad 141$

$353 \quad 72$

377

48

\section{Excluding GD and WWII}
$\pi$
$0.179 * * \quad-0.001$
$0.133 * * * \quad-0.000$
$0.074 * *$
$-0.001$
(0.069)
(0.002)
(0.041) (0.002)
(0.037)
(0.002)

F-value
\# Observations

$$
3.64 * *
$$

$5.76 * * *$

2.08

\# Observations

$260 \quad 123$

323

60

340

43

Before WWII

$$
\pi
$$

$$
0.262 * * * \quad-0.071
$$

$0.246 * * * \quad-0.035$

(0.058)

$0.121^{*}$

(0.068)

$-0.070$

(0.068)

F-value

\# Observations

(0.073)

(0.068)

7.76

183

17
$2.73 *$
$190 \quad 10$

$174^{6.10^{* * *}}$

0.184

(0.166)

After WWII $\pi$

$$
94^{0.64} 103
$$

\begin{tabular}{ccccccccc} 
F-value & \multicolumn{3}{c}{0.64} & \multicolumn{3}{c}{0.84} & \multicolumn{3}{c}{0.37} \\
\# Observations & 94 & & 103 & 148 & 49 & 161 & 36
\end{tabular}

Note: OLS estimates of relationship between inflation and growth using White's heteroskedasticity correction. ***, **, and * indicate statistical significance at 1\%, 5\% and $10 \%$ confidence levels respectively. 


\section{Table 4: Inflation Volatility and Growth}

\subsection{Linear and non-linear specifications}

Dependent Variable:

Average Income Growth

Full Sample

Non-Linear

Linear Non-Linear

Specification Specification
Excluding GD and WWII

Linear Non-Linear

Specification

Specification

$\begin{array}{ccccc}\pi & 0.091 * * & 0.187 * * * & 0.077 * * & 0.110^{*} \\ \pi^{2} & (0.035) & (0.061) & (0.031) & (0.060) \\ & & -0.009 * * & & -0.003 \\ \sigma_{\pi}^{2} & & (0.004) & & (0.005) \\ & & & & -0.002 \\ \text { \# Observations } & -0.003 & -0.002 & -0.003^{*} & (0.002) \\ & (0.002) & (0.002) & (0.002) & 351\end{array}$

\subsection{Samples split by inflation}

\section{Dependent Variable: Average Income Growth}

$\pi \leq 5 \% \quad \pi>5 \% \quad \pi \leq 10 \%$

$\pi>10 \%$

$\pi \leq 15 \%$

$\pi>15 \%$

\section{Full Sample}

$\begin{array}{ccccccc}\pi & 0.323^{* * *} & 0.003 & 0.149 * * * & 0.003 & 0.110^{* *} & 0.003 \\ & (0.074) & (0.002) & (0.052) & (0.002) & (0.048) & (0.002) \\ \sigma_{\pi}^{2} & 0.001 & -7.42 \mathrm{e}-06 * * & -0.002 & -7.69 \mathrm{e}-06^{* * *} & -0.004^{*} & -7.64 \mathrm{e}-06^{* * *} \\ & (0.003) & (3.08 \mathrm{e}-06) & (0.003) & (2.77 \mathrm{e}-06) & (0.002) & (2.79 \mathrm{e}-06)\end{array}$

F-value

$10.10^{* * *}$

\# Observations

$284 \quad 141$

$4.56 * *$

2.19

$\begin{array}{llll}353 & 72 & 377 & 48\end{array}$

\section{Excluding GD and WWII}

$\begin{array}{lcccccc}\pi & 0.182^{* *} & 0.003 & 0.132^{* * *} & 0.003^{*} & 0.080^{* *} & 0.003 \\ \sigma_{\pi}^{2} & (0.076) & (0.002) & (0.042) & (0.002) & (0.036) & (0.002) \\ & 0.001 & -7.69 \mathrm{e}-06 * * & -0.000 & -8.15 \mathrm{e}-06 * * * & -0.004 * * & -8.05 \mathrm{e}-06 * * * \\ & (0.004) & (3.09 \mathrm{e}-06) & (0.003) & (2.45 \mathrm{e}-06) & (0.002) & (2.63 \mathrm{e}-06)\end{array}$

\begin{tabular}{crrrrrr} 
F-value & \multicolumn{2}{c}{$3.40^{* *}$} & \multicolumn{2}{c}{$5.60 * * *$} & \multicolumn{2}{c}{2.08} \\
\# Observations & 260 & 123 & 323 & 60 & 340 & 43
\end{tabular}

Estimates on constant coefficients have been suppressed and are available upon request. 
Figure 1: Inflation and Growth

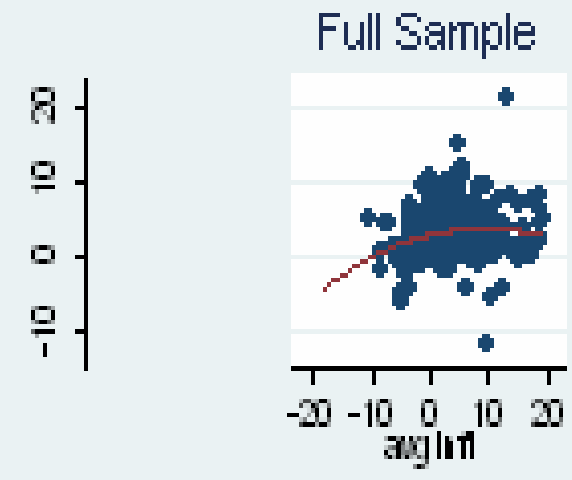

- aggront
Ftted walres

\section{Pre-LMWl}

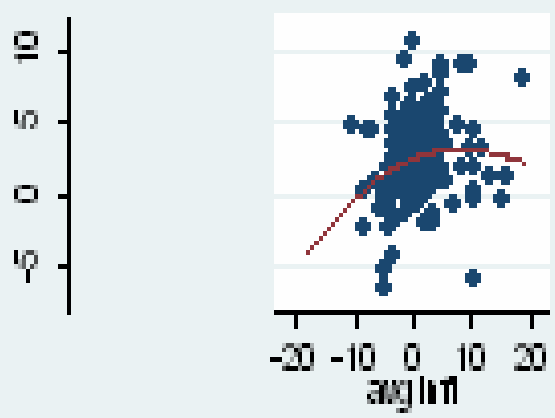

- aggrout
Fltadualus
Excluding 60 and Whil

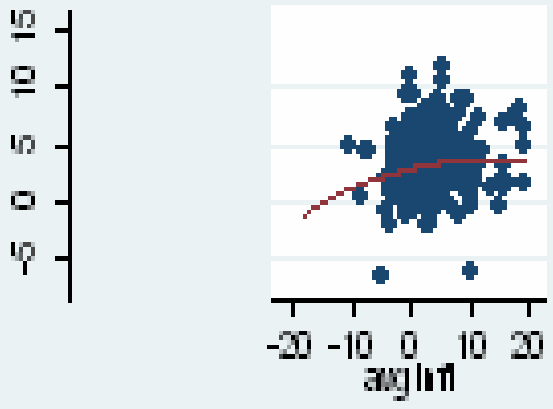

- aggront L Flteduales

\section{Post-iwh}

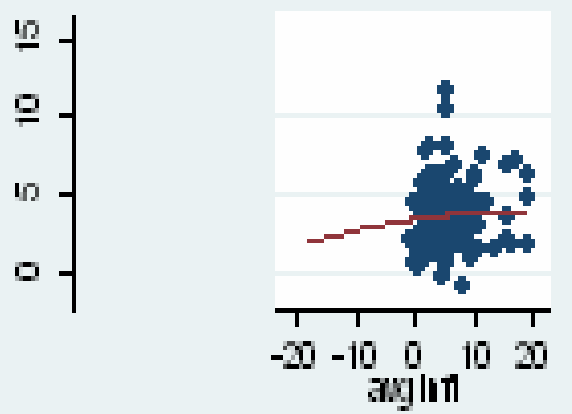

+ aggront
Flted uales 